\title{
AVALIAÇÃO DE MAPAS TOPOGRÁFICOS 3D PARA NAVEGAÇÃO VIRTUAL
}

\author{
Evaluation of 3D topographic maps for virtual navigation \\ MARCIO AUGUSTO REOLON SCHMIDT ${ }^{1}$ \\ LUCIENE STAMATO DELAZARI ${ }^{2}$ \\ ${ }^{1}$ Universidade Federal de Uberlândia \\ Faculdade de Engenharia Civil \\ ${ }^{2}$ Universidade Federal do Paraná \\ Programa de Pós-Graduação em Ciências Geodésicas \\ marcioschmidt@feciv.ufu.br; luciene@ufpr.br
}

\begin{abstract}
RESUMO
O uso de representações cartográficas em visualizações tridimensionais reúne as vantagens dos avanços tecnológicos, mas enfrenta a falta do conhecimento necessário para construi-las adequadamente segundo a ótica da comunicação cartográfica. As consequências incluem equívocos no projeto cartográfico que restringem a compreensão das feições representadas e suas relações espaciais. Um dos possíveis usos para mapas 3D é a navegação virtual apoiada por mapas topográficos tridimensionais. O problema da determinação da orientação relativa e da seleção de pontos de referência em ambientes virtuais são agravados pela falta de conhecimento de como os usuários reagem às diferenças perceptivas propostas pela alteração perspectiva da imagem. Portanto, esta pesquisa apresenta a estratégia de comparar os croquis realizados a partir de representações 3D com aqueles de mapas topográficos convencionais para identificação de quais feições são selecionadas como pontos de referência e suas características. A abordagem de avaliação combina o protocolo Think Aloud e questionários. Os 43 voluntários selecionados produziram 179 croquis que foram avaliados pelas técnicas descritas e também pela análise estatística de Kruskall-Wallis. Através da identificação do número de pontos de referência, a topologia e a orientação entre eles foi possível encontrar evidências de sucesso da proposta para navegação com mapas topográficos 3D.
\end{abstract}

Palavras-chave: Mapa Topográfico 3D; Navegação Virtual; User-Centred Design. 
ABSTRACT
The use of cartographic representations in 3D views gathers the advantages of technological advances, but it faces a lack of knowledge needed to build them properly from the point of view of cartographic communication. Consequences include misconceptions in map design that can restrain or even impair the understanding of represented features and their spatial relations. One use for 3D maps is virtual navigation supported by three-dimensional topographic maps. The problem of determination of relative orientation and the selection of reference points on virtual environments is aggravated by the lack of knowledge of how users react to the new perspective and perceptive differences proposed by it. Therefore, this research presents the comparison of sketch-maps made from 3D representations with those from conventional topographical maps to identify which features are used for navigation. The test methodology combines the Think Aloud protocol and questionnaires. The 43 volunteers selected produced 179 sketch maps that were evaluated by the qualitative methods described above and by the Kruskall-Wallis statistical method as well. By identifying the number of reference points, the topology among them and the orientation for the whole sketch map, we were able to find evidences of the success in the proposal to navigate with $3 \mathrm{D}$ topographic maps.

Keywords: 3D Topographic Maps; Virtual Navigation; User-Centered Design.

\section{INTRODUÇÃO}

O uso e o dinamismo de mapas em 3D são fortalecidos pela capacidade de manipulação e armazenamento de dados computacionais associados à interatividade e à mudança de ponto de vista, que são fundamentais para criar um senso de realidade virtual. Em ambientes de realidade virtual não-imersiva (RVNI), as representações são imagens tridimensionais apresentadas na tela de monitores de modo a manter o usuário fora da cena. No entanto, o conhecimento cartográfico necessário para construir essas representações não se desenvolveu da mesma forma que o desenvolvimento tecnológico. Dependendo do nível de detalhe, soluções para generalização, simbologia, interatividade, projeto de interface e as deformações causadas pela vista perspectiva, o resultado pode ser uma representação inconsistente e de difícil entendimento (SCHMIDT E DELAZARI, 2010).

A construção de representações $3 \mathrm{D}$ e seu impacto sobre os usuários têm sido discutidos na literatura por vários autores nos últimos anos, com destaque para Vinson (1999), Darken e Peterson (2001), Haeberling (2002), Tory et al (2004), Harrower e Shessley (2005) e Haeberling et al (2008). No entanto, a determinação da orientação e distâncias relativas não é uma tarefa trivial em ambientes virtuais. A hipótese dos autores é que a simbologia 3D deve permitir aos usuários determinar sua posição e orientação relativas e estimar as distâncias às posições dos pontos de referência globais e locais da representação, para tomar decisões táticas e estratégicas para ir de um lugar a outro. 
De forma a contribuir para este assunto, este trabalho apresenta os resultados da aplicação de técnicas da cartografia temática para a diferenciação dos símbolos em mapas topográficos 3D. O trabalho apresenta os resultados de testes com 43 voluntários, geógrafos e cartógrafos, para avaliar a aplicação da simbologia 3D para a tarefa de navegação. Os resultados dos testes evidenciaram como este tipo de simbologia é percebido e como a distribuição espacial dos símbolos é armazenada no mapa cognitivo do usuário.

\section{ESTRUTURA COGNITIVA DA NAVEGAÇÃO}

Darken e Sieber (1993) definem a navegação como o processo pelo qual o usuário determina a sua posição e orientação relativas a outros elementos da paisagem e usa esse conhecimento para chegar a outros locais. Este processo envolve o conhecimento declarativo, necessário para identificar o que existe no campo de visão, o conhecimento configuracional para determinar como as feições se relacionam e o conhecimento procedural para a tomada de decisões de navegação. Além disso, a navegação é fortemente baseada na leitura de mapas para se conhecer a região. Para propor mapas topográficos $3 \mathrm{D}$ para navegação é preciso, portanto, inicialmente entender como as pessoas navegam e como relacionam seus conhecimentos à leitura de mapas.

Segundo a teoria de Marr (1982 apud MACEACHREN, 1995), a visão, principal ferramenta da navegação, pode ser entendida como um processo que se inicia com o estímulo visual como reações químicas do sistema ocular segundo as diferenças de intensidade luminosa refletida por objetos. Em um segundo momento estes estímulos são agrupados em linhas e áreas separadas como forma de criar um esboço primário. Ocorre então ação de processos internos do cérebro no reconhecimento e interpretação dessas imagens na tentativa de discriminar e localizar objetos na imagem. A última etapa é a criação de uma imagem tridimensional, que ocorre somente após exposições mais prolongadas ou sob diferentes pontos de vista.

Esta discriminação das feições representadas no mapa ou na realidade ocorre através do arsenal disponível pelo sistema visual humano que contempla o grupo de fatores da Gestalt e a separação figura fundo. Estes parâmetros são aplicados nas duas primeiras etapas de Marr. Como consequência o que se vê são feições e símbolos completos e não seus elementos geométricos e texturas que o compõem separadamente. Além da formação da figura partir das unidades visuais fornecidos pela Gestalt existe a separação figura fundo com seus parâmetros, dentre os quais se destacam o contraste relativo e o contorno.

Tanto em ambientes reais como na leitura de mapas, os objetos são mais ou menos destacados em função da variação de sua posição, tom de cor, valor de cor e saturação. A combinação destas características desperta a atenção que permite a seleção das feições ou objetos e a sua gravação na memória de curto prazo. Dessa forma, a primeira proposição desta pesquisa é que é possível criar uma simbologia com a finalidade de despertar a atenção seletiva para certas feições e símbolos do 
mapa através das variáveis visuais aplicadas à simbologia $3 \mathrm{D}$ e estimular a sua relação na memória de curto-prazo.

O próximo passo é criação de uma estrutura geral da cena, com as posições relativas principalmente dos pontos de referência (PR), passada para a memória de curto prazo a partir da atenção seletiva. A partir do mapa cognitivo, em seus vários graus de completude, são aplicados os esquemas de conhecimento (declarativo, organizacional e procedural) que permitem uma pessoa realizar a navegação. À medida que as representações internas são atualizadas e melhoradas com exposições periódicas e contínuas, é possível passar de um esquema de pontos para outro nível mais alto como rotas e a partir dele como o de terreno.

Estas diversas representações internas ou mapas cognitivos são armazenados em uma macroestrutura. Porém, não se guarda uma única representação da área, mas, segundo Pinker (2009), é armazenada uma série de representações particulares em diferentes escalas que se relacionam através dos PR. Dessa forma, os PR podem ser divididos em dois grupos: locais e globais. Isto remete à teoria de Vinson (1999) que recomenda que pontos de referência globais sejam percebidos como a mesma feição em diferentes escalas. Portanto, para navegar com sucesso, as pessoas devem planejar os seus movimentos utilizando uma associação dos conhecimentos espaciais adquiridos sobre o ambiente e armazenados no mapa mental representativo da área. Golledge (1992) identifica os componentes básicos do conhecimento espacial como identidade, localização, magnitude e temporalidade do fenômeno. Destes, a localização se torna essencial à navegação, pois dela derivam os conceitos de distância, ângulo relativo e direção (azimutes), sequência de pontos de referência e extremos de rotas e conexão de pontos de referência e rotas.

Mesmo que os mapas cognitivos não sejam cartograficamente equivalentes o relacionamento espacial de algumas feições presentes na representação e no mundo real, com os quais o indivíduo consegue relacioná-los, deve estar correto (GOLLEDGE E GÄRLIN, 2003). Assim como um mapa só será efetivo na medida em que o usuário reconhece os PR na representação e no seu ambiente real, a mesma comparação entre representações $2 \mathrm{D}$ e $3 \mathrm{D}$ é válida no contexto desta pesquisa. Esta é a segunda proposição para a simbologia, pois se pode criar uma representação para favorecer o potencial de lembrança da feição na memória de curto prazo dos usuários.

\section{MÉTODO}

A avaliação desta abordagem passa pelas etapas de construção do mapa 3D e testes com usuários especialistas. A primeira etapa envolve a determinação dos dados fonte e o projeto cartográfico. Em seguida diferentes cenas do mesmo mapa foram apresentados a usuários cartógrafos e geógrafos para avaliação do entendimento da proposta do mapa 3D. 


\subsection{Construção dos Mapas Topográficos 3D}

No contexto desta pesquisa foi importante que a região fosse desconhecida para os voluntários de modo a evitar que o conhecimento prévio da região pudesse influenciar os resultados. Portanto, os dados básicos foram obtidos da base cartográfica de 2007 do IPPUC para a cidade de Curitiba, na escala 1:10.000 e a ocupação e uso do solo foi modificada com base na interpretação de aerofotos do município de Uberlândia (MG), na mesma escala, de 2010. O projeto cartográfico considerou a classificação das feições segundo o mapeamento sistemático brasileiro na escala 1:50.000 e, por isso, as curvas de nível foram interpoladas para uma equidistância de 10 metros. Esta estrutura foi selecionada por permitir melhor adequação do modelo aos pontos coletados e permitir incluir linhas de quebra para suavizar a transição entre feições como, por exemplo, o terreno e uma rodovia.

A proposição para construção dos símbolos seguiu a organização proposta por Haeberling (2002) composta de três passos: proposição geométrica, proposição visual e proposição de visualização. O primeiro passo pode ser entendido como a definição dos objetos em modo wireframe nos softwares CAD e sua distribuição na representação. Também está envolvida a posição relativa dos objetos que auxiliam o usuário a extrair e a entender a informação representada, como malha de coordenadas e toponímias. A proposição visual trabalha com as variáveis visuais tamanho, tom e valor de cor, textura e padrão, orientação e com os aspectos gráficos especiais como a reflexão de superfícies. O último passo se refere ao conjunto de fatores que influenciam a percepção da simbologia. Este grupo é formado pela iluminação da cena, sombras decorrentes da posição relativa entre feições e da posição e do tipo da iluminação, efeitos atmosféricos e ambientais, estrutura do céu (cor e esmaecimento), parâmetros de câmera como abertura e profundidade de campo, e nível de detalhamento.

Nesta pesquisa, a proposição geométrica utilizou forma, tamanho e posição das feições. Na proposição visual foram estudadas as luminosidades dos símbolos e na proposição de visualização foram avaliados os parâmetros de câmera (ângulo de abertura (fov) e atitude deixada fixa), a cor do céu e a iluminação da cena. O processo é interativo, ou seja, cada passo da proposição pode ser reavaliado caso o resultado final não seja adequado à comunicação cartográfica, segundo a sensibilidade do cartógrafo. A Figura 1 apresenta um esquema das etapas envolvidas no projeto cartográfico.

Em cinza médio estão indicadas as variáveis testadas na diferenciação dos símbolos usados como pontos de referência, em cinza escuro as variáveis comuns à representação geral e aos pontos de referência e, por último, em cinza claro, a variação da cor do céu e as configurações de câmera que podem influenciar na percepção das demais variáveis. Cada um destes aspectos exprime diferentes efeitos aparência dos símbolos das cartas topográficas 3D. Entretanto, existem muitas possibilidades para se combinar cada grupo de aspectos e cada alteração no seu espectro de variação produz um efeito específico na aparência final do símbolo (HAEBERLING, 2002). Dessa forma, o uso do mapa se torna importante para 
orientar as soluções que o cartógrafo pode tomar na construção da simbologia. Como resultado a simbologia de representações cartográficas $3 \mathrm{D}$ deve ser construída de forma semelhante à cartografia temática, mesmo para cartas topográficas. A proposição geométrica também considera o grau de realismo, que é a generalização cartográfica aplicada aos símbolos. A proposição geométrica, nesta etapa, foi construída de forma mais abstrata que Petrovic e Masera (2004) e mais realista que a cartografia topográfica convencional. $\mathrm{O}$ resultado dos mapas com as variáveis visuais é mostrado na Figura 2. Na Figura 2a, as setas indicam aplicação da variável tamanho às estradas e às árvores. $\mathrm{Na}$ Figura $2 \mathrm{~b}$ estão indicadas as modificações dos telhados e copas de árvores pela alteração da forma.

Figura 1 - Esquema do projeto cartográfico 3D proposto.

Fonte: Autor.

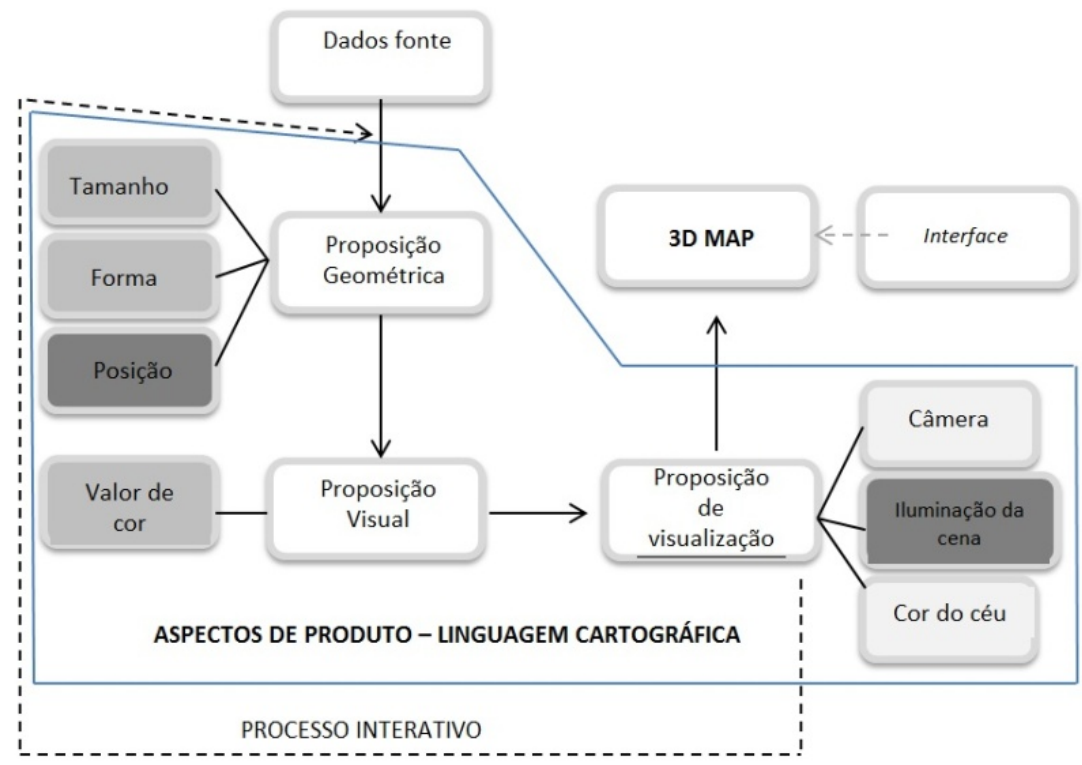

\subsection{Testes}

Foram desenvolvidos quatro testes que avaliaram a influência da variação do ângulo de abertura e atitude da câmera, e as características dos pontos de referência nas proposições de simbologia na capacidade de navegação dos usuários. O total de participantes foi de 43 voluntários sendo 22 da Universidade Federal do Paraná (UFPR) e 21 da Universidade Federal de Uberlândia (UFU). Os voluntários geraram 179 croquis e 43 formulários que foram analisados segundo os critérios de número de pontos de referência e das diferenças das estimativas de posição, de distância e de orientação relativas.

Bol. Ciênc. Geod., sec. Artigos, Curitiba, v. 18, nº 4, p.532-548, out-dez, 2012. 
Figura 2 - Exemplos dos mapas 3D produzidos com diferentes variáveis visuais ( $a$-tamanho e b - forma, indicação por flechas).

Fonte: Autor.

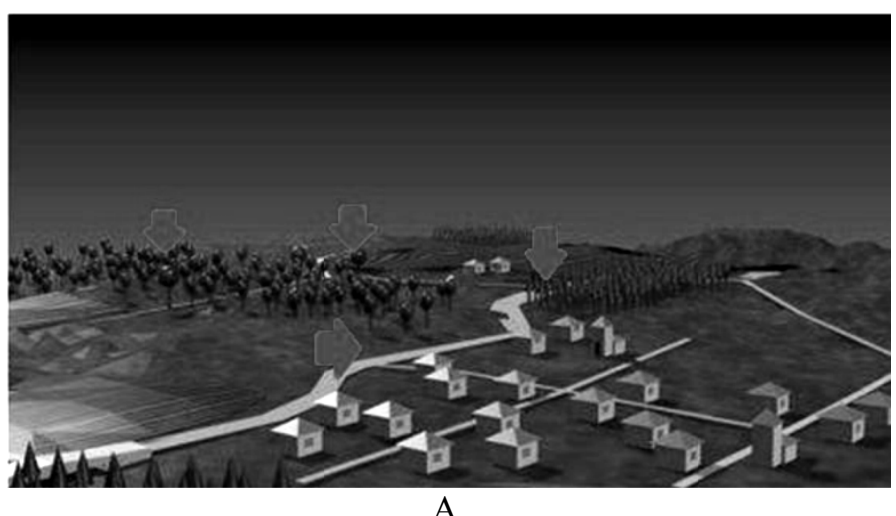

A

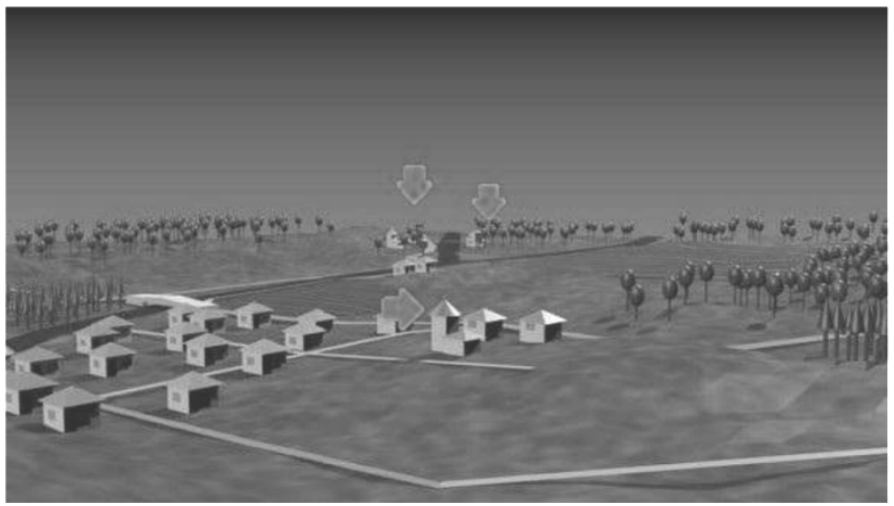

B

A execução dos testes se iniciou com a identificação do perfil do usuário, através de perguntas de múltiplas escolhas. Estas perguntas tentaram identificar o nível de instrução em cartografia do usuário, seus hábitos de navegação enquanto dirige ou caminha, tempo de formação, tempo que trabalha na área de produção de mapas, idade, entre outras. Estas informações podem contribuir na variação da cognição espacial (MONTELLO, 2002) e, ainda que seja difícil estabelecer relacionamentos entre estas características, seu uso não deve ser descartado, pois o objetivo é evidenciar vícios de leitura de mapas ou outros problemas no seu uso que o próprio usuário pode desconhecer. Em seguida, foram realizados os testes com mapas. 
O primeiro teste analisou a influência do ângulo de abertura da câmera na percepção de distâncias relativas em duas situações: com e sem a presença de uma grade semelhante à grade de coordenadas da projeção UTM. Em cada um deles os usuários leram os mapas por cerca de 1 minuto e após desenharam os croquis. $\mathrm{O}$ reduzido tempo de exposição evita, ao menos em parte, que a representação interna na memória de curto prazo seja elaborada e processada com informações adicionais de experiências anteriores com mapas 3D. A tarefa geográfica neste primeiro teste foi identificar qual o caminho mais curto dentre os três que estavam representados. Os caminhos se iniciavam no centro da imagem em direção noroeste até o fundo da imagem. Na primeira parte do teste, cada imagem tinha um fov diferente, sendo $42^{\circ}$, $46^{\circ}$ e $50^{\circ}$. O valor de $46^{\circ}$ foi definido por Haeberling et al (2008), e as variações de $\pm 4^{\circ}$ decorrem do ângulo relativo à visão periférica.

O objetivo dos outros testes foi identificar quais das variáveis visuais selecionadas são eficientes em maior ou menor grau na identificação dos símbolos, observando o contexto de separação figura-fundo, na formação de agrupamentos e classes de símbolos, para seleção dos pontos de referência e posterior formação de rotas. A primeira variável visual testada foi o tamanho. Uma imagem impressa com a simbologia padrão de uma região diferente do teste anterior foi apresentada ao usuário e foi utilizada a instrução: "Siga a estrada a partir da igreja mais ao norte e dirija-se ao replantio de pinheiros mais ao sul". Após produzir um croqui uma nova imagem, desta vez com a simbologia modificada, foi apresentada com a mesma instrução para a produção de um novo croqui. Ao final foi questionado ao participante se ele ou ela conseguiu identificar ordem ou hierarquia em alguma classe perceptível nesta imagem.

A segunda variável visual testada foi o valor de cor. Uma região do mesmo mapa 3D, distinta das demais, foi apresentada com as modificações na simbologia nas estradas e em algumas árvores próximas às mudanças de direção nas estradas (Figura 2a). A hierarquia foi inserida entre subclasses de um tipo de feição, por exemplo, estradas principais, secundárias e vicinais. Neste teste perguntou-se a descrição do caminho entre dois pontos visíveis no mapa, caso a pessoa estivesse dirigindo. Novamente foram apresentadas duas imagens, uma com a simbologia padrão e uma com a simbologia com a variável visual aplicada e, após, foi questionado sobre hierarquia de classes e subclasses. $\mathrm{O}$ procedimento foi repetido no terceiro teste cuja variável visual aplicada foi a forma. As copas das árvores que se encontram nas proximidades da bifurcação do rio foram alteradas de esferas ou cones para cubos, e os telhados as edificações que ficam próximas à linha de visada da câmera foram alteradas de pirâmides com base quadrada para cones (Figura 2b). Neste caso, o objetivo foi avaliar a percepção à mudança na forma dos símbolos, pois a pergunta sobre ordem não faz sentido por se tratar de uma variável visual que representa o nível de medida nominal. .

A estratégia adotada é comparar os croquis dos mapas 2D e 3D da mesma região como forma de obter evidências que permitam inferir sobre a percepção do mapa. Por isso, ao final da sessão de testes um mapa topográfico em escala 1:50.000 
foi apresentado e os voluntários desenharam mais uma vez um croqui. A função do uso deste mapa foi avaliar a capacidade do participante em ler um mapa com simbologia convencional em vista exocêntrica.

Salienta-se que para diminuir as variáveis de análise, como capacidade de interação e de uso de ferramentas de navegação que não são pertinentes a esta pesquisa, os testes foram realizados com uso dos mapas topográficos 3D impressos, através dos quais foram elaborados os respectivos croquis. A partir dos destes croquis foram calculadas as frequências das respostas dos voluntários segundo os critérios da quantidade de feições representadas, a recordação das suas características e a estimativa da posição relativa entre as feições. Posteriormente, estas informações e as frequências relativas foram analisadas estatisticamente para se determinar os graus de significância das respostas em relação à proposição desta pesquisa.

Do total de participantes foram selecionados aleatoriamente $12,5 \%$ entre os participantes dos testes, ou seja, cinco participantes, para a realização do teste Think Aloud. Esta decisão foi tomada em função da grande demanda de tempo e recursos que o método exige para sua realização e análise. $\mathrm{O}$ protocolo foi executado individualmente no laboratório com o usuário sentado em frente a uma mesa, na qual, para cada teste, diferentes imagens do mapa 3D foram mostradas em sucessão. À medida que o usuário interagia com os mapas narrava suas ações e impressões em voz alta. As informações obtidas por este tipo de análise foram úteis para identificar quais são os pontos de referência utilizados no cumprimento da tarefa de navegação, uma vez que ao desenhar o croqui os usuários lembram, processam e aplicam seus esquemas mentais na determinação da posição e das características das feições lembradas e, portanto, os pontos de referência e suas características não são necessariamente os mesmos desenhados.

\section{RESULTADOS}

Os resultados dos questionários mostram que o grupo de participantes é composto por mestres e doutores (54\%), por mestrandos (21\%) e uma fração de estudantes de graduação em fase de conclusão, sendo que $60 \%$ dos voluntários tem experiência profissional. As perguntas que tratam do uso de mapas e do conhecimento de projeto cartográfico apontam que $86 \%$ dos voluntários afirmaram usar mapas com muita frequência, porém só ocasionalmente constroem estes mapas pessoalmente $(83,7 \%)$. Outra característica é que os mapas são geralmente digitais sendo utilizados atlas interativos (11,6\%), programas CAD $(18,6 \%)$ e SIG $(46,5 \%)$. Apesar disso, a maioria dos participantes afirma ter pouca experiência com produção de cartas topográficas, sendo sua produção concentrada em mapas temáticos. A frequência com que o fazem também é relativamente baixa, apenas $42 \%$ ocasionalmente produzem mapas. Outro grupo de questões identificou que 95\% dos voluntários afirmou conhecer as tarefas de localização e navegação usando mapas, ainda que 32,5\% tenha afirmado sentir dificuldades em usar mapas topográficos para navegação. Sobre os hábitos de navegação $76,8 \%$ fazem 
caminhadas frequentes e 90,6\% costumam dirigir com muita frequência ou cotidianamente. Além disso, ao se deslocar, $86 \%$ dos participantes afirmaram que costumam variar o caminho com certa frequência.

Uma das primeiras questões que se destacam nas análises dos croquis é que 93\% dos voluntários desenharam o mapa conforme o ponto de vista da cena, ou seja, nas vistas perspectivas as feições localizadas acima do terreno foram desenhadas em perspectiva (Figura 3). Quando o croqui da carta topográfica convencional foi solicitado, as mesmas feições foram desenhadas em vista exocêntrica. $\mathrm{O}$ número de ocorrências se destaca, ainda que não seja estatisticamente significativo $(\mathrm{p}<0,156038)$. Os resultados obtidos apontam que os usuários não habituados com representações $3 \mathrm{D}$ não realizam qualquer transformação perspectiva entre as vistas e os símbolos são entendidos próximos ao esboço primário da imagem (Figura 3a).

A observação dos croquis também evidencia que nos mapas $3 \mathrm{D}$ os pontos de referência adotados com maior frequência são aqueles que se encontram acima do MDT, ou seja, casas e árvores (Figura 3a). Por outro lado, ao usar mapas com a representação convencional (Figura $3 b$ ) os croquis assumem o ponto de vista exocêntrico e as representações passam a ser agrupadas por área e não mais por símbolos individuais.

Uma justificativa pode ser consequência da proposição do teste, pois cada participante tinha apenas 1 minuto para analisar a imagem antes de desenhar os croquis. Como consequência, os croquis apresentam poucas feições e estas são bastante generalizadas. Outra justificativa é consequência do ponto de vista estático das imagens, pois na vista egocêntrica, a não movimentação da câmera permite ao usuário avaliar somente um lado do símbolo. Isto remete à teoria de Marr, que afirma que a representação interna de um símbolo passa pela necessidade da exposição continuada e em detalhes do símbolo. Pode-se supor que a pequena exposição criou nos participantes uma imagem $2,5 \mathrm{D}$ e que a passagem de uma vista 3D para 2D, na verdade, apresente maiores dificuldades. Estas duas afirmações concordam com a verbalização de um dos participantes no Teste 1, que afirmou sentir dificuldades em passar da vista perspectiva para planta ao fazer o croqui.

Um terceiro fator que se destaca nesta discussão é a associação dos símbolos pelo participante e os princípios da Gestalt. Em 95\% dos croquis desenhados a partir das imagens 3D, a distribuição espacial das árvores e das casas não foi percebida como parte de um conjunto ou de uma mesma classe, mas como feições individuais. Dessa forma, os resultados apresentam a forte influência que o ponto de vista exerce na identificação e no reconhecimento de um símbolo. Além da perspectiva apresentada nos croquis, muitos desenhos não têm relação direta com a forma dos símbolos sendo estas, às vezes, substituídas por representações particulares do voluntário. 
Figura 3 - Croqui produzido por voluntário do teste com a variável forma: a) no mapa 3D, e b) no mapa 2D.

Fonte: Autor.

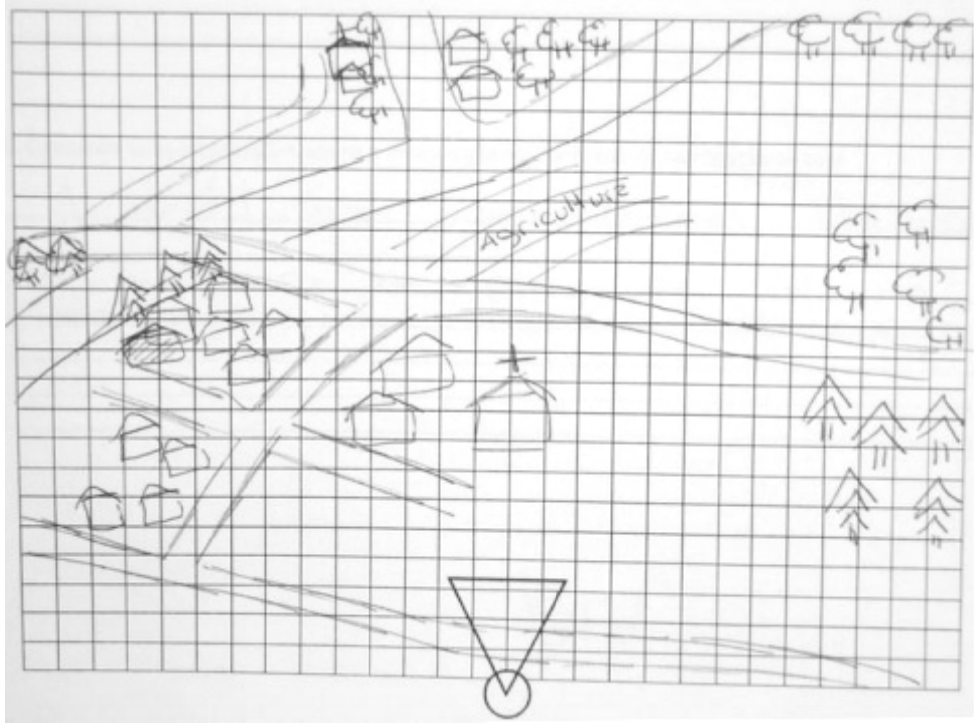

a

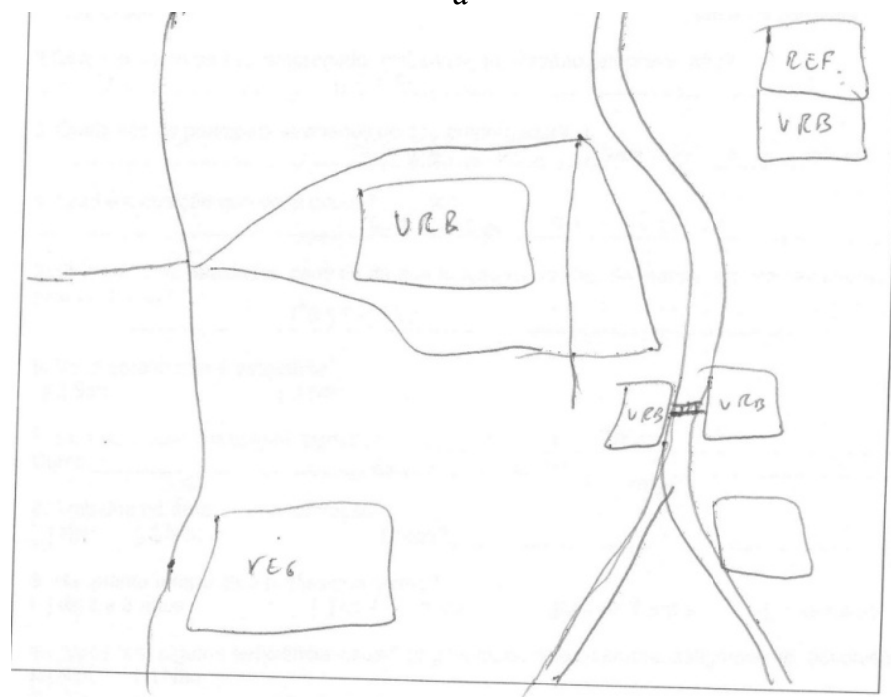

b

Bol. Ciênc. Geod., sec. Artigos, Curitiba, v. 18, no 4, p.532-548, out-dez, 2012. 
Os resultados obtidos no primeiro teste indicam que a variação de $\pm 4^{\circ}$ no ângulo de abertura das imagens não altera a percepção dos participantes de forma significativa. $O$ número de acertos no Teste 1 foi significativo a $0,06(\mathrm{p}<0,053434)$. O teste também constatou que aproximadamente $85 \%$ dos participantes preferem a imagem com o ângulo de abertura de $42^{\circ}$ para tomar a decisão de qual caminho é o menor, contrariando o valor de $46^{\circ}$ obtido por Haeberling et al (2008) em testes com especialista suíços. $\mathrm{Na}$ segunda parte deste teste, 40 voluntários preferiram a presença da grade colocada logo acima do DTM. Esta preferência pode ser explicada pela ação dos participantes de usar os intervalos da malha como um apoio visual, contando os intervalos. Apesar de 7 pessoas terem optado por refazer os croquis após ver a grade sobre o mapa, a maioria decidiu não refazer os desenhos, usando a malha para confirmar que o caminho escolhido era o menor e se sentir mais confiante. A maioria dos participantes do teste Think Aloud não percebeu mudanças na distribuição espacial das feições representadas em função da presença da grade. Contudo, com a presença da grade, os participantes afirmaram ter menos confusão sobre o posicionamento relativo dos símbolos, desde que a grade esteja próxima ao MDT. Mesmo assim, todos alegaram que a grade polui a representação quando está em uma posição alta em relação ao MDT. Desta forma, a dificuldade de se observar as feições por baixo da grade prejudica o efeito de comparação, que é perdido, e a visualização dos símbolos prejudicada. Neste teste, outro ponto de destaque é que as feições concentradas próximas à linha de visada da câmera tendem a ser lembradas com maior facilidade, desde que sejam discrimináveis. Com efeito, o número de feições representadas ao longo da linha de visada é maior no centro da imagem do que nas áreas à direita ou esquerda desta linha. Estes indícios revelam que a atenção seletiva tem maior intensidade no centro da cena.

Nos testes com as variáveis visuais, os resultados foram influenciados pela iluminação da cena e cor do céu. Estes dois fatores contribuíram para alterar a percepção do usuário em relação a tons de cor e, como consequência, no contraste relativo para a separação da figura fundo. Por outro lado, o número de acertos indica que variações em valor de cor são mais influentes do que em forma e em tamanho. Os resultados dos testes com essa variável visual foram os que obtiveram o maior número de acertos $(95,4 \%)$ em relação ao número de pontos de referência identificados e a sua topologia. Isto pode ser explicado pela característica dos símbolos, uma vez que as variáveis forma e tamanho são bastante suscetíveis aos processos construtivos dos símbolos. De maneira geral, a diferenciação por valor de cor é fortemente influenciada pela luminosidade da cena provida pela cor do céu, pois em relação à hierarquia dentro das classes percebidas na imagem com céu azul, somente $32 \%$ dos participantes informaram reconhecer esta variável visual na representação das estradas.

Os resultados do teste com a variável tamanho mostraram que 17 pessoas (40\%) informaram corretamente um dos caminhos possíveis e 26 pessoas $(60 \%)$ erraram a resposta devido a erros de orientação. Apesar de 12 participantes $(28 \%)$ reconhecerem a variável visual tamanho, especialmente quando aplicada na 
representação das estradas, nenhum registro foi feito em relação às árvores. Uma justificativa é que o efeito perspectivo e as configurações da cena têm forte influência na percepção desta variável visual e consequentemente na hierarquia das classes, como no caso das estradas. Isto demonstra a dificuldade de se usar esta variável visual em mapas 3D. Os resultados deste teste indicaram os piores resultados para a orientação geral dos croquis. Nos testes Think Aloud os participantes expressaram perceber poucas diferenças entre imagens e a identificação da variação em tamanho não foi reconhecida adequadamente.

Os croquis representados com a variável visual forma obtiveram os piores resultados na identificação dos pontos de referência. Apenas cinco leitores $(11,6 \%)$ identificaram mudanças de forma nos telhados das igrejas ou nas árvores, apesar destes pontos de referência estarem concentrados próximos à linha de visada. Além disso, os erros no número de feições representadas e a topologia apresentaram maiores distorções do que nos mapas com outras variáveis visuais.

Os croquis foram analisados segundo o número de pontos de referência e a posição topológica. As frequências computadas das respostas foram comparadas com aquelas equivalentes nos croquis das cartas topográficas. Os valores obtidos para orientações relativas foram avaliadas com o MapAnalyst, segundo metodologia de Dillemuth (2009). A estratégia adotada foi a de identificar se existe significância entre as respostas como forma de evidenciar que a simbologia proposta é adequada para a navegação, considerando-se a comunidade usuária e seus hábitos de navegação. Como a simbologia testada parte do princípio das cartas topográficas de referência geral, as semelhanças dos resultados são consideradas um fator positivo e que contribui para adoção desta estratégia de representação.

Os valores do teste de Kruskall-Wallis (1952), mostrados na tabela 1, indicam que não há relação entre o número de pontos de referência (NUM) identificados nas cartas $2 \mathrm{D}$ e $3 \mathrm{D}$, ao passo que a sua posição topológica (POS) foi significativa para o teste de ângulo de abertura e o teste com a variável visual valor de cor. Este resultado sugere que algum conhecimento em cartografia temática é importante para a correta interpretação do mapa 3D. Para verificação desta afirmação foram cruzadas algumas informações do formulário sobre instrução em cartografia e hábitos de navegação com a quantidade de pontos de referência identificados e suas posições topológicas. Nesta tabela valores críticos foram desconsiderados da análise. No cruzamento das frequências da Tabela $1 \mathrm{com}$ as frequências dos formulários para grau de instrução e tempo de atuação profissional (A e B) foi encontrada correlação significativa entre o número de acertos na posição relativa dos pontos de referência para o teste $1(\mathrm{p}<0,0026)$ e para o número de pontos identificados no teste com a luminosidade $(\mathrm{p}<0,0271)$. Na tabela 1 são identificadas correlações positivas para a posição dos PR nos testes de tamanho e forma $(\mathrm{p}<0,0267$ e $\mathrm{p}<0,0108$, respectivamente). 
Tabela 1 - Significância pelo teste de Kruskall-Wallis (5\%) para os pontos de referência dos croquis em relação à carta topográfica. A - Nível de instrução; B Anos na profissão; C- Costuma caminhar; D- Costuma dirigir.

*Valores tomados com número diferente de participantes $(\mathrm{n}=15)$

\begin{tabular}{c|c|c|c|c|c|c|c}
\hline Teste & $\begin{array}{c}\text { Num } \\
\text { PR }\end{array}$ & Topol. & $\begin{array}{c}\text { Orien } \\
\text { Rel }\end{array}$ & $\begin{array}{c}\text { Num+ } \\
\text { A+B }\end{array}$ & $\begin{array}{c}\text { POS+ } \\
\text { A+B }\end{array}$ & $\begin{array}{c}\text { NUM+ } \\
\text { C+D }\end{array}$ & $\begin{array}{c}\text { POS+ } \\
\text { C+D }\end{array}$ \\
\hline Fov & 0,9472 & 0,0188 & 0,0054 & $9,666 \mathrm{e}-6$ & 0,0026 & $2,027 \mathrm{e}-8$ & 0,0002 \\
\hline Valor & 0,6662 & 0,0110 & $4,86 \mathrm{e}-4$ & 0,0271 & 0,0008 & 0,0012 & $1,58 \mathrm{e}-4$ \\
\hline Tamanho & 0,4602 & 0,1075 & 0,4647 & $1,045 \mathrm{e}-4$ & 0,0527 & $3,425 \mathrm{e}-7$ & 0,0267 \\
\hline Forma & 0,2982 & 0,7179 & 0,00031 & $3,53 \mathrm{e}-6$ & 0,0705 & $2,654 \mathrm{e}-8$ & 0,0108 \\
\hline
\end{tabular}

Entretanto, as limitações da vista 3D prejudicam o desenvolvimento de um mapa único da área, de forma a exigir mais tempo de interação do que com a o mapa em vista exocêntrica. Os indícios coletados nos testes apontam que os participantes, de maneira geral, não conseguiram concatenar as quatro vistas usadas nos testes em um único mapa representativo da área. A maioria dos participantes percebeu cada vista 3D como uma representação semelhante, porém distinta das demais. A exceção foram aqueles estudantes e professores que trabalham diretamente com a produção de mapas. Isto pode sugerir alguma restrição em relação ao tipo de usuário de acordo com a especificidade da representação.

\section{CONCLUSÕES}

Não foi possível identificar evidências de que a variação de $\pm 4^{\circ}$ no ângulo de abertura da câmera altere a percepção dos participantes. Entretanto, o paradigma do mapa topográfico se fez presente ao se avaliar a presença da grade de referência. De maneira geral, os usuários preferem a presença da grade de coordenadas próximas ao MDT como forma de ancorar suas decisões espaciais. Esta metáfora de orientação não foi testada para modelos com grandes variações altimétricas, mas os participantes do teste apresentaram-se mais seguros em estimar posições, distâncias e orientações relativas com a presença da mesma.

Para as cartas 3D, os símbolos construídos com formas semelhantes ao objeto real facilitam a leitura do mapa, mas os problemas da vista obliqua limitam a exploração espacial de regiões. Nas imagens desenvolvidas nesta pesquisa o ponto de vista fixo não permitiu que o usuário criasse uma imagem tridimensional do objeto, mas apenas o contorno separado da imagem de fundo pelo contraste relativo. Aparentemente os usuários não habituados com representações 3D não realizam qualquer transformação perspectiva entre as vistas, e os símbolos são entendidos próximos ao esboço primário da imagem. Ainda assim, a posição das feições em relação à posição do observador também se mostrou um fator importante, pois se identificou maior concentração dos pontos de referência nas proximidades da linha 
de visada. Estes indícios apontam que a atenção seletiva tem maior intensidade no centro da cena.

Em geral, as edificações e as árvores não foram percebidas como grupos, mas como feições individuais. Através dos resultados pode-se concluir que a não associação da simbologia em grupos pela maior parte dos participantes dos testes se deve a problemas de proximidade e tamanho relativo, conceitos da Gestalt, e à influência da iluminação no contraste relativo.

A cor do céu tem forte influência na luminosidade dos PR, em especial naqueles símbolos mais afastados do ponto de vista do usuário. Mesmo quando os símbolos estavam localizados próximos à linha de visada, quase metade dos participantes dos testes não identificou a resposta correta com o céu cinza. $\mathrm{O}$ problema se repetiu com as variáveis visuais tamanho e forma. Quando o céu tem cor azul (tons claros) o número de identificações corretas aumentou para mais de $85 \%$ nos três casos. Neste contexto, a luminosidade (valor de cor) tem maior potencial para diferenciação de $\mathrm{PR}$, ao passo que a forma apresentou os piores resultados em todos os testes. O tamanho, para este fim, apresenta o inconveniente de sofrer forte influência das configurações de câmera, o que consequentemente atrapalha a identificação de hierarquia de classes. As correlações estatísticas apresentadas nos resultados permitem considerar que, apesar das variáveis visuais utilizadas nesta pesquisa auxiliarem a busca visual de feições para serem selecionadas como pontos de referência, a posição do símbolo e sua relação com o restante da representação pode ser mais importante do que sua aparência, conforme Forest e Castner (1985), MacEachren (1995).

Através das proposições e testes desta pesquisa foi possível comprovar, ainda que não de forma conclusiva para todos os parâmetros, que o projeto cartográfico de mapas 3D deve considerar o uso de conceitos da cartografia temática. Como consequência, as representações que adotam esta abordagem apresentam grande poder de comunicação cartográfica e se assemelham à comunicação realizada pela cartografia topográfica convencional.

\section{AGRADECIMENTOS:}

Ao CNPQ pela bolsa de doutorado entre 2008 e 2009 e pela bolsa produtividade em pesquisa Processo 306862/2011-5

\section{REFERÊNCIAS BIBLIOGRÁFICAS}

DARKEN, R.P., e PETERSON, B. Spatial Orientation, Way finding, and Representation. Handbook of Virtual Environment Technology. Stanney, K. Ed. 2001.

DARKEN, R. P, e SIBERT, J. L. A Toolset for Navigation in Virtual Environments. 6th annual ACM Symposium on User Interface Software and Technology UIST'93. 1993. ACM 0.89791.628-X. Atlanta, United States. Disponível em: www.acm.org. Acessado em: 18-08-09. 
GOLledGE, R.G. Do People Understand Spatial Concepts: The Case of FirstOrder Primitives. Working Paper UCTC No. 211. 1992. Disponível em http://www.uctc.net/papers/211.pdf. Acessado em 12-01-2011.

GOLLEDGE,R.G e GÄRLIN, T. 2003. Cognitive maps and urban travel. , Handbooks in Transport series. V5, pp 501-512, ISSN 1472-7889. Elsevier.Disponivel em: http://web.mit.edu/ asevtsuk/Public/fall2010/ Advance_Seminarin_City_Form_Fall2010/readings/class4/Golledge\%202003 $\% 20$ Cognitive $\% 20 \mathrm{Maps} \% 20$ and $\% 20$ Urban\%20Travel.pdf. Acessado em: $23-$ 03-2010

HAEBERLING, C. 3D-map presentation: A Systematic Evaluation of Important Graphic Aspects. Anais do ICA Mountain Cartography Workshop "Mount Hood". 2002. International Cartographic Association. Disponível em: http://www.mountaincartography.org/mt_hood/pdfs/haeberling2.pdf Acessado em: 21/07/09.

HAEBERLING, C., BÄR,H., HURNI,L. Proposed Cartographic Design Principles for 3D maps: A contribution to an Extended Cartographic Theory. Cartographica v. 43. i.3. pp.175-188. 2008.

HARROWER,M. E SHESSLEY,B. 2005. Moving Beyond Novelty: Creating Effective 3D Fly-Over Maps. Anais: 22 $2^{\text {th }}$ International Cartographic Conference Mapping Approaches into a Changing World. La Coruña, Spain, July 9-16, 2005. Disponivel em: http://www.geography.wisc.edu/ harrower/pdf/ICA2005 paper.pdf. Acessado em: 24-07-09.

KRUSKAL, W. H. AND WALLIS, W.A. Use of Ranks in One-Criterion Variance Analysis. Journal of the American Statistical Association, vol. 47, No. 260. 1952. pp. 583-621. Disponível em: http://links.jstor. org/sici?sici=01621459\%28195212\%2947\%3A260\%3C583\%3AUORIOV\%3E2.0.CO\%3B2-A. Acessado em: 08/01/2012

MACEACHREN, A. How Maps Work: Representation, Visualization and Design. 1995. ISBN 0-89862-589-0. Guilford Press,. United States.

MONTELLO D.R. (2002). Cognitive Map-Design Research in the Twentieth Century: Theoretical and Empirical Approaches. Cartography and Geographic Information Science. V 29. N3. pp 283-304. Disponível em: www. geography.wisc.edu/histcart/ v6initiative/12montello.pdf. Acessado em: Last visited 23-11-2010.

PETROVIČ, D., MAŠERA, P. 2004. Analysis of user's response on 3d cartographic presentations. Anais: 7th meeting of the ICA Commission on Mountain Cartography, Bohinj, Slovenia. Disponível em; www.mountaincartography. org/...06/16_Petrovic_Masera.pdf Acessado em; 10-09-2008.

PINKER, S. Como a Mente Funciona, 2ed. Companhia das letras. 2009. ISBN 97885-7164-846-3

SCHMIDT, M.A.R. e DELAZARI, L.S. 2010. Proposta de metodologia para testes qualitativos de mapas 3D. Boletim de Ciências Geodésicas. Vol. 16 , N. 4. UFPR. 
TORY,M., MÖLLER, T., ATKINS, M.S., KIRKPATRICK, A.E. 2004. Combining 2D and 3D Views for Orientation and Relative Position Tasks. Anais: CHI 2004, V.6 N.1, Austria doi ACM:1-58113-702-8/04/0004.

VINSON, N.G. Design Guidelines for Landmarks to Support Navigation in virtual environments. Anais do CHI '99. Pittsburgh, USA. pp. 278-285. 1999. Disponível em: $\quad \mathrm{http} / /$ nparc.cisti-icist.nrc-nrc.gc.ca/npsi/ctrl?action= rtdocean $=9147118$ earticle $=12$ Acessado em: 01-08-09.

(Recebido em junho de 2012. Aceito em agosto de 2012.) 